\title{
Evaluation of Common Experience of Neurosurgery and Pediatric Intensive Care Unit on Pediatric Head Trauma under the Light of Current Literature: Analysis of 96 Cases
}

\author{
Mehmet Sabri Gürbüz ${ }^{1}$, (1) Muhterem Duyu²
}

${ }^{1}$ Department of Neurosurgery, Istanbul Medeniyet University Faculty of Medicine, Istanbul, Turkey

${ }^{2}$ Department of Pediatric Health and Diseases, Istanbul Medeniyet University Faculty of Medicine, Pediatric Intensive Care Unit, Istanbul, Turkey

\begin{abstract}
Introduction: This study aimed to evaluate the features and injury mechanisms of pediatric head trauma, demographics of the patients and factors affecting the outcome and to present the common experience of neurosurgery and pediatric intensive care unit (PICU) in light of the current literature.

Methods: Ninety-six of 110 children under the age of 18 who had sufficient data and were treated in PICU for head trauma between 2014 and 2018 were evaluated retrospectively. The association between age, sex, mechanism of injury, neurological examination at presentation, Glasgow coma scale (GCS) score, history of cardiopulmonary resuscitation, shock, blood glucose level, hypoxia, convulsion, mean arterial pressure, heart rate per minute, body temperature, intracranial pressure (ICP) values, surgical interventions and Glasgow outcome scale (GOS) scores was investigated.

Results: There were 32 patients (33.3\%) in mild head trauma group, 28 patients (29.1\%) in moderate head trauma group and 36 patients (37.5\%) in severe head trauma group. Isolated head trauma was present in 49 patients, and multitrauma was observed in the remaining. The rate of favourable outcome was $72.9 \%$ (70 patients), and that of unfavourable outcome was $27.1 \%$ (26 patients) with the mortality rate of 15.6\%. A moderate and negative correlation between presenting GCS scores and presenting blood glucose levels (rho: $-0.422 \mathrm{p}<0.001$ ), and a moderate and positive correlation between presenting GCS scores and presenting body temperature were observed (rho: $0.422 \mathrm{p}<0.001$ ). A highly significant positive correlation was observed between GCS and 1-year GOS scores (rho: 0.762 p<0.001).

Discussion and Conclusion: Analyzing the characteristics of pediatric head trauma, knowing the prognostic factors, developing a common algorithm and standardizing the management parallel to current literature will contribute to a favourable prognosis.

Keywords: Child; Glasgow outcome scale; guideline; Head trauma; intracranial pressure; pediatric; prognosis.
\end{abstract}

$\mathrm{T}$ raumatic brain injury has been reported as the leading cause of mortality and morbidity in the pediatric age group. In particular, the increase in urbanization, construction of skyscrapers and the widespread use of motor vehicles are the most important factors that can be prevented ${ }^{[1]}$. Although the injury sites and mechanism of injury are similar to adults, they differ from adults in terms of pathophysiology and management. Age-related variables, 
structural differences, given that the child is a developing individual and the difficulties of fully evaluating the neurological examination play a role ${ }^{[2]}$.

In the United States, 475.000 children are exposed to head trauma each year, while 37.000 of them are hospitalized and 2.685 of them die ${ }^{[3]}$. Especially in children under four years of age, mortality and disability rates have been reported to be higher than other age groups with the addition of child abuse rates ${ }^{[4]}$. It has been reported that sports injuries are very common in children older than one year and children are the victims of $60-80 \%$ of total sports injuries [5]. Between 1997 and 2007, 73,276 children were reported to die from traumatic brain injury and related complications in the United States ${ }^{[6]}$. Corso et al. ${ }^{[7]}$ calculated the lifetime cost of children under the age of 14 who suffered from a traumatic brain injury as $\$ 60.4$ billion.

It is necessary to know the pathophysiology and prognostic factors of head trauma to improve the results of pediatric head traumas, especially severe head traumas, and to succeed in the treatment aiming to reduce the damage caused by secondary injury ${ }^{[2]}$. In the last 30 years, factors, such as the safety of motor vehicles and the development of infant seat technology, increased use of helmets, the development of intensive care equipment, the advancement of monitoring techniques and the increase in the number of experienced personnel have led to the improvement of the outcomes of head trauma.

Understanding the importance of providing management of treatment by calculating cerebral perfusion pressure (CPP) by monitoring intracranial pressure (ICP) especially in severe head trauma and its frequent use by pediatric Intensive Care Unit (PICU) specialists and neurosurgical specialists have improved the results even though to a small extent ${ }^{[8,9]}$. However, there is not enough data about how widespread ICP monitoring is used in PICUs in our country.

It has been repeatedly emphasized and included in the literature that it is essential to follow published guidelines, manage the treatment according to these guidelines and to refer this patient group to experienced, equipped advanced centers to achieve effective outcomes in pediatric head trauma ${ }^{[10]}$. This research aims to present the results of 96 pediatric severe head trauma cases treated by neurosurgery and PICU in the light of current literature.

\section{Materials and Methods}

\section{Patients}

Since the pediatric patient group is defined as individuals aged under 18 years in many guidelines ${ }^{[11]}$, our series includes children of this age group. A total of 110 patients under 18 years of age who were treated in the PICU between 2014-2018 with the diagnosis of head trauma were retrospectively analyzed. Ninety-six patients with complete records and one year Glasgow Outcome Scale (GOS) values were included in the study. Patients who presented to the emergency trauma unit of our hospital, and also patients who were referred to our hospital from external centers were enrolled in our study. The patients were taken to the PICU immediately after their first evaluation in the Emergency Department.

Age, gender, injury types, additional organ injuries, presenting Glasgow Coma Scale (GCS) values, cardiopulmonary resuscitation (CPR), pupillary reactions at admission, shock status, blood sugar values, hypoxia, seizure, mean arterial pressure, heart rate, body temperature, mechanical ventilation, brain CT examination, neurosurgical surgical interventions and ICP values were examined from hospital records. Then, 1-year GOS (Table 1) values were recorded by calling the families or the patient if he/she was alive.

\section{Treatment Approach}

As soon as the patients were admitted to the clinic, the first physical and neurological examinations were performed and the patients were classified as having mild (GCS: 14$15)$, moderate (GCS: 9-13), and severe (GCS $\leq 8)$ head traumas. After the hemodynamic and respiratory stabilization of the patients, laboratory and radiological examinations

Table 1. Glasgow outcome scale

\begin{tabular}{lcllc}
\hline Outcome & Score & & Definition \\
\hline Good recovery & 5 & Minimal disability not interfering with normal daily activities & Favorable prognosis \\
Moderate disability & 4 & Disable but not dependent on someone for care, and can work, in sheltered workplaces & $(4$ and 5) & Unfavorable \\
Severe disability & 3 & Open conscious ness but needs care during daily life and can not return to work & prognosis \\
Vegetative state & 2 & Absence of awareness of self and environment & $(1-3)$ \\
Dead & 1 & He/she is not living &
\end{tabular}


were planned. In patients with severe head trauma, Grade 4 patients according to Marshall Brain Computed Tomography (CT) criteria ${ }^{[12]}$ were first monitored with ICP monitoring device (Integra Camino ${ }^{\circledast}$ Pressure Monitoring Catheter Kits). Patients who could not undergo ICP monitoring were followed up by intermittent neurological examinations and radiological imaging (Fig. 1 a-f). Magnetic Resonance Imaging (MRI) was used to determine the degree of injury and hence, to estimate the prognosis of the patients with diffuse axonal injury (Fig. 2a-c).

In the initial evaluation of brain CT of the patients, the neurosurgery team performed emergency surgery if there was a condition requiring surgical intervention regardless of the severity of the head trauma (Fig. 1a, c). Unilateral decompressive craniectomy was performed in addition to the evacuation of hematoma in patients with a significant shift in midline structures $(>5 \mathrm{~mm})$ together with hematoma
(Fig. 3a-b). If there was no requirement for surgical intervention, follow-up and treatment in cooperation with the neurosurgery department were started. Bilateral decompressive craniectomy was performed in patients with severe head trauma whose ICP values were $>20 \mathrm{mmHg}$ and did not regress despite maximal medical therapy (Fig. 4ab). In patients whose ICP values were presumably high or conceivably high based on $\mathrm{CT}$ examination according to Marshall criteria, medical treatments aimed at lowering ICP were administered in accordance with the triage and doses specified in the guidelines. Intermittent neurological examinations were performed and recorded to monitor treatment outcome.

\section{Statistical Analysis}

Descriptive data were shown as $\mathrm{n}, \%$ values in categorical data and median 25-75 percentile values in contin-
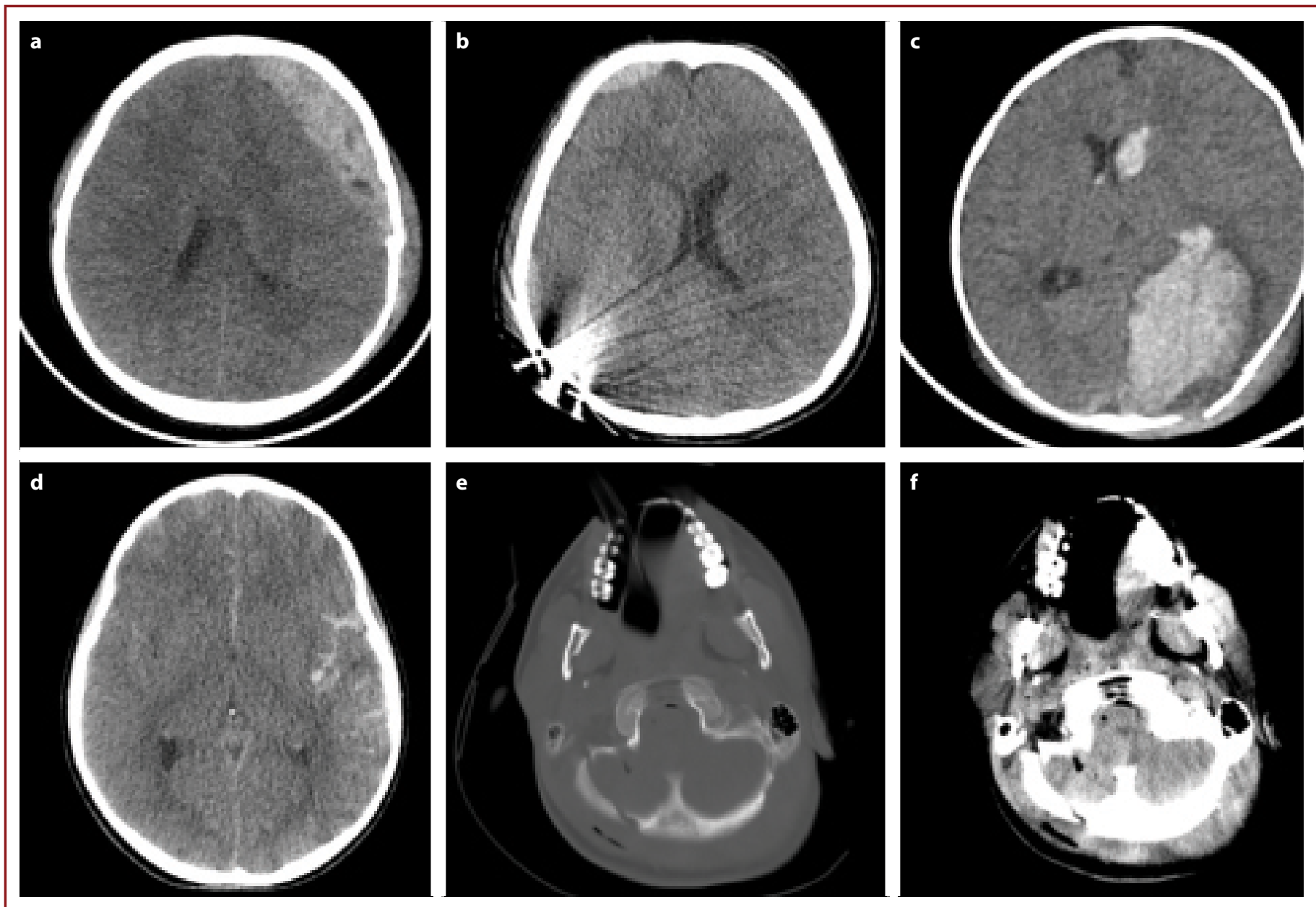

Figure 1. (a) Axial non-contrast cranial CT scan shows left frontoparietal acute subdural hematoma and left parietal fracture. (b) Axial non-contrast cranial CT scan shows right frontal epidural hematoma and cochlear implant artifact. (c) Axial non-contrast cranial CT scan shows left occipital intracerebral hematoma, left frontal horn hematoma and left occipital fracture line. (d) Axial non-contrast cranial CT scan shows traumatic subarachnoid hemorrhage in the left silvian fissure and left parietal region. (e) Right occipital linear fracture is seen in axial non-contrast cranial CT scan (f) Axial non-contrast cranial CT demonstrating right occipital linear fracture and pneumocephalus. 


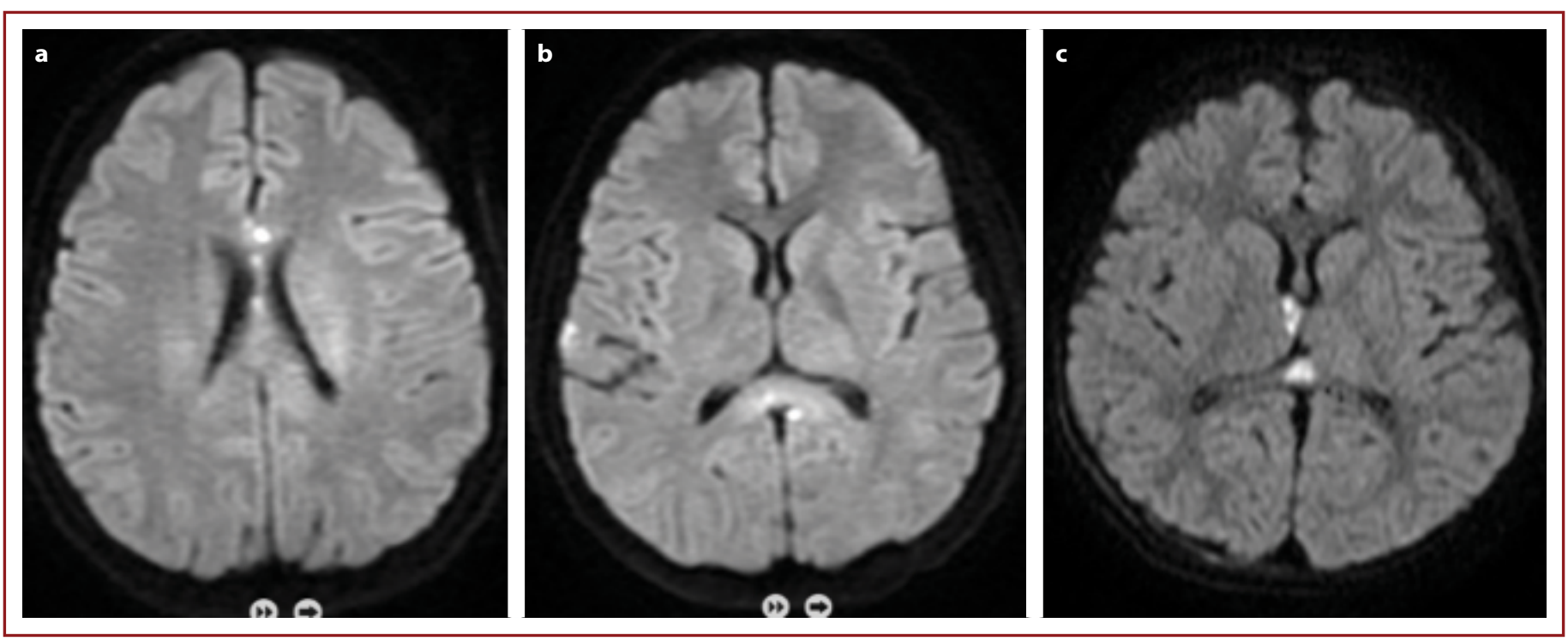

Figure 2. (a-c) Axial diffusion cranial MRI studies of three different patients show areas of restricted diffusion characteristic of diffuse axonal injury.

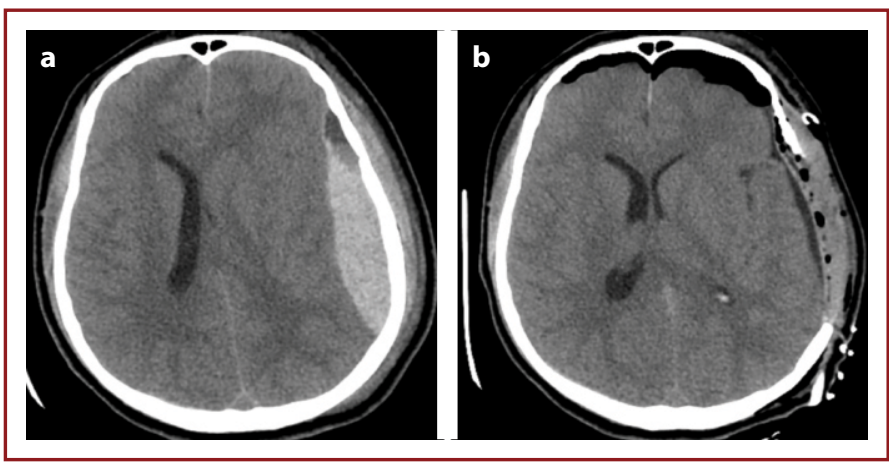

Figure 3. (a) Axial non-contrast cranial CT scan shows left frontoparietal acute subdural hematoma and shift in midline structures. (b) Postoperative cranial CT examination of the same patient revealed that the hematoma was evacuated and unilateral decompressive craniectomy was performed on the hematoma side.

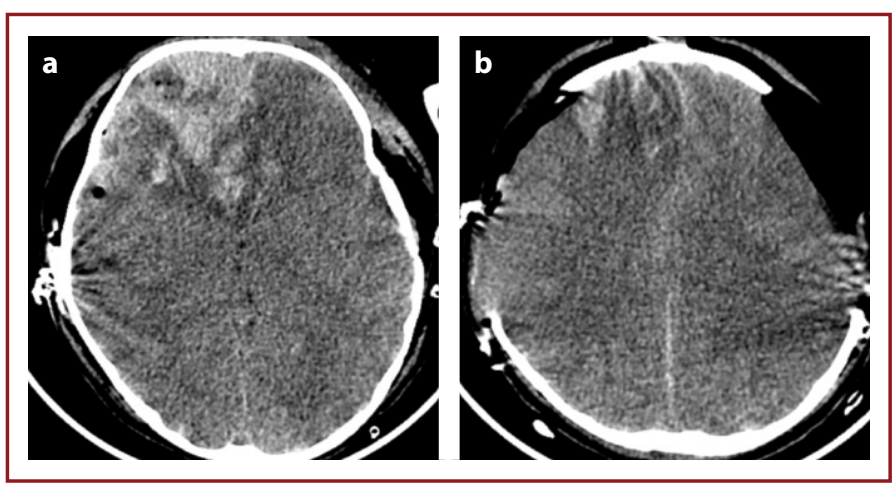

Figure 4. (a) Axial noncontrast cranial CT scan shows areas of intracerebral hematoma, subarachnoid hemorrhage, contusion and pneumocephaly in the right frontal area. (b) Postoperative cranial CT of the patient who had undergone bilateral decompressive craniectomy reveals that sufficiently wide craniectomy had been performed.

uous data. Chi-square and Fisher's tests were used to compare categorical data. Measured data were tested by Kolmogorov-Smirnov tests for the assumption of normal distribution. Mann-Whitney $U$ test was used to compare the non-normally distributed measurement data. Spearman correlation analysis was used to investigate the correlation of two measurements. For all analyzes, $p<0.05$ was accepted as the level of statistical significance. The analyses were performed using IBM ๑ SPSS 20 version software.

\section{Results}

Of the 96 cases included in this study, 63 (65.6\%) were male and 33 (34.4\%) were female. The ages of the patients ranged from 29 days to 17.6 years, with a mean age of $6.16 \pm 5.09$ years. When the GOS scores were classified as favorable and unfavorable results (Table 1), $72.9 \%$ (70 patients) of the patients were found to have a poor outcome at 1-year follow-up and 26 patients (27.1\%) had a good prognosis. Of 96 patients in the series, 15 (15.6\%) died within one year.

Falling from height ranked first with a rate of $56.3 \%$. Motor vehicle accidents (in-vehicle and out-of-vehicle traffic accidents) ranked second (34.4\%). No significant relationship was found between the type of injury and GCS scores (Table 2). Our series consisted of 49 patients with isolated head trauma, 31 multi-trauma cases with predominantly head trauma and 16 multi-trauma patients with mainly abdominal and thoracic trauma. The GCS values were significantly lower in multi-trauma patients presenting predominantly with head trauma compared to those without $(p<0.001)$, and GCS values were significantly higher in multi-trauma patients presenting mainly with thoracic trauma relative to those without $(p<0.001)$ (Table 3).

The cases in our series were grouped according to GCS scores in line with the recommendation cited in the litera- 
Table 2. Mechanisms of injury and their correlations with GCS, and GOS

\begin{tabular}{|c|c|c|c|c|c|c|c|c|}
\hline & \multirow[b]{2}{*}{$\mathbf{n}$} & \multirow[b]{2}{*}{$\%$} & \multirow[b]{2}{*}{$\begin{array}{c}\text { GCS (median } \\
\text { (25-75 Percentile)) }\end{array}$} & \multicolumn{4}{|c|}{ GOS(n) } & \multirow{2}{*}{$\mathbf{p}$} \\
\hline & & & & $\mathbf{n}$ & $\%$ & $\mathbf{n}$ & $\%$ & \\
\hline \multicolumn{9}{|l|}{ Mechanism of Injury } \\
\hline Fall from height & 54 & $(56.3)$ & $5.0(3.0-5.0)$ & 40 & $(74.1)$ & 14 & $(25.9)$ & 0.272 \\
\hline Fall of TV & 5 & $(5.2)$ & $4.0(3.0-5.0)$ & 3 & $(60.0)$ & 2 & $(40.0)$ & \\
\hline Blunt trauma of the head & 2 & $(2.1)$ & $5.0(5.0-5.0)$ & 2 & $(100.0)$ & 0 & $(.0)$ & \\
\hline Fall from stairs & 1 & $(1.0)$ & $1.0(1.0-1.0)$ & 0 & $(.0)$ & 1 & $(100.0)$ & \\
\hline Fall down from a bike & 1 & $(1.0)$ & $3.0(3.0-3.0)$ & 0 & $(.0)$ & 1 & $(100.0)$ & \\
\hline
\end{tabular}

GCS: Glasgov coma scale, GOS: Glasgov outcome scale.

ture ${ }^{[13]}$. Patients had been exposed to mild ( $\left.n=32: 33.3 \%\right)$, moderate $(n=28: 29.1 \%)$ and severe $(n=36: 37.5 \%)$ head traumas. In addition, a linear relationship between GCS, and GOS (Glascow Outcome Scale) scores was observed. When the relationship between GCS and blood glucose, mean blood pressure, heart rate, body temperature and GOS scores at the end of one year was examined; there was a moderately negative significant correlation (rho: -0.422 $\mathrm{p}<0.001$ ) between presenting GCS scores and blood glucose levels, and a moderately positive significant correlation between presenting GCS scores and body temperature (rho: $0.422 \mathrm{p}<0.001$ ) (Table 4).

In addition, a significant positive correlation was found between the presenting GCS and one year GOS scores (rho: $0.762 p<0.001$ ). GCS scores were found to be significantly lower in patients who underwent CPR, in patients whose pupillary reflexes could be elicited in cases presented with anisocoria, patients who were in shock at admission, in individuals with neurological diseases, and in patients treated with mechanical ventilation compared to patients without these indicated criteria $(p<0.001)$ (Table 3 ).

Favourable outcomes had been achieved in indicated number of patients who underwent hematoma surgery $(n=2 ; 10 / 2: 20 \%)$, ICP monitoring ( $n=1 ; 1: 9: 11 \%)$, and decompressive craniectomy $(n=1 ; 1 / 10 ; 10 \%)$. The high rate of poor outcome was due to the fact that 17 out of 18 patients already belonged to the group of severe head trauma. The average GCS scores in the groups of hematoma surgery, decompressive craniectomy and ICP monitoring were 5.6, 4.8 and 5.3 respectively.

\section{Discussion}

Pediatric brain injury is different from that of adults in terms of both injury types and its effects. Secondary dam- age caused by trauma results in less oxygen and metabolite access to the neural tissue and inability to remove metabolic residues and toxins. With the addition of vasogenic and/or cytotoxic edema to the clinical picture, pathologies, such as increased ICP, herniation syndromes, brain stem compression and focal ischemia are inevitably seen ${ }^{[14,15]}$. Damage may increase exponentially, especially in the case of hypotension, hypoxia, hyperglycemia and seizures. Initially mild or moderate head trauma can turn into severe head trauma.

As a result, in many developed countries, more than half of child deaths result from traumatic brain injury which corresponds to approximately 18 times the tumor-related deaths ${ }^{[1]}$. Of the 96 patients in our series, 15 (15.6\%) died within one year and unfortunately this figure may increase in long-term follow-up. When we add three patients who live a vegetative life, this rate increases to $18.7 \%$. The incidence rate of poor prognosis was $27.1 \%$ with the addition of 8 patients with severe disability.

Considering types of injuries, falling from height and motor vehicle accidents lead the way in children under 14 years of age. In children under the age of four, child abuse is also included in the clinical picture ${ }^{[3]}$. In our series, fall from height (56.3\%) and motor vehicle accidents (34.4\%) were the most frequent injury mechanisms observed in parallel with the literature. This reveals the necessity of obeying the traffic rules, the importance of the wearing seat belt and use of safe baby seat. The data show how careful parents and caregivers should be, and that education and awareness should be raised.

It is clear that the education process for trauma prevention should start at school age. Furthermore, public services, such as wide pavements, appropriate pedestrian crossings and bicycle lanes, especially to avoid non-vehicle traffic ac- 
Table 3. The association between presenting findings of the patients and their GOS scores is demonstrated

\begin{tabular}{|c|c|c|c|c|c|}
\hline & \multicolumn{4}{|c|}{ 1-year-GOS } & \multirow[t]{3}{*}{$\mathbf{p}$} \\
\hline & \multicolumn{2}{|c|}{ Favorable } & \multicolumn{2}{|c|}{ Unfavorable } & \\
\hline & $\mathbf{n}$ & $\%$ & $\mathbf{n}$ & $\%$ & \\
\hline \multicolumn{6}{|c|}{ Isolated head trauma } \\
\hline No & 15 & $(57.7)$ & 32 & $(45.7)$ & 0.297 \\
\hline Yes & 11 & $(42.3)$ & 38 & $(54.3)$ & \\
\hline \multicolumn{6}{|c|}{ Multiple trauma, predominantly head trauma } \\
\hline No & 11 & $(42.3)$ & 54 & $(77.1)$ & 0.001 \\
\hline Yes & 15 & $(57.7)$ & 16 & $(22.9)$ & \\
\hline \multicolumn{6}{|c|}{ Multiple trauma, predominantly chest trauma } \\
\hline No & 26 & $(100.0)$ & 54 & $(77.1)$ & 0.008 \\
\hline Yes & 0 & $(0.0)$ & 16 & $(22.9)$ & \\
\hline \multicolumn{6}{|l|}{ CPR } \\
\hline No & 19 & (73.1) & 70 & $(100.0)$ & $<0.001$ \\
\hline Yes & 7 & $(26.9)$ & 0 & $(0.0)$ & \\
\hline \multicolumn{6}{|c|}{ Pupillary reflex } \\
\hline No & 11 & $(42.3)$ & 4 & $(5.7)$ & $<0.001$ \\
\hline Yes & 15 & $(57.7)$ & 66 & $(94.3)$ & \\
\hline \multicolumn{6}{|c|}{ Anisocoria at admission } \\
\hline No & 22 & $(84.6)$ & 67 & $(95.7)$ & 0.063 \\
\hline Yes & 4 & $(15.4)$ & 3 & $(4.3)$ & \\
\hline \multicolumn{6}{|c|}{ Shock at presentation } \\
\hline No & 6 & $(23.1)$ & 58 & (82.9) & $<0.001$ \\
\hline Yes & 20 & $(76.9)$ & 12 & $(17.1)$ & \\
\hline \multicolumn{6}{|c|}{ Admission hypoxia } \\
\hline No & 20 & (76.9) & 67 & $(95.7)$ & 0.005 \\
\hline Yes & 6 & $(23.1)$ & 3 & $(4.3)$ & \\
\hline \multicolumn{6}{|c|}{ Neurologic deterioration } \\
\hline No & 13 & $(50.0)$ & 66 & $(94.3)$ & $<0.001$ \\
\hline Yes & 13 & $(50.0)$ & 4 & $(5.7)$ & \\
\hline \multicolumn{6}{|c|}{ Seizures } \\
\hline No & 21 & $(80.8)$ & 64 & $(91.4)$ & 0.145 \\
\hline Yes & 5 & $(19.2)$ & 6 & $(8.6)$ & \\
\hline \multicolumn{6}{|c|}{ Mechanical ventilation } \\
\hline No & 0 & $(0.0)$ & 54 & $(77.1)$ & $<0.001$ \\
\hline Yes & 26 & $(100.0)$ & 16 & $(22.9)$ & \\
\hline \multicolumn{6}{|c|}{ Hematoma surgery } \\
\hline No & 18 & $(69.2)$ & 68 & $(97.1)$ & $<0.001$ \\
\hline Yes & 8 & $(30.8)$ & 2 & $(2.9)$ & \\
\hline \multicolumn{6}{|c|}{ ICP catheter } \\
\hline No & 18 & $(69.2)$ & 69 & $(98.6)$ & $<0.001$ \\
\hline Yes & 8 & $(30.8)$ & 1 & $(1.4)$ & \\
\hline \multicolumn{6}{|c|}{ Decompression } \\
\hline No & 18 & $(69.2)$ & 68 & $(97.1)$ & $<0.001$ \\
\hline Yes & 8 & $(30.8)$ & 2 & $(2.9)$ & \\
\hline
\end{tabular}

GOS: Glasgov outcome scale, CPR: Cardiopulmonary resuscitation, ICP: Intracranial pressure.

cidents, will also be effective in preventing traumatic brain injuries. As a result, any treatment modality no matter how effective it is will not be more life-saving than taking measures to prevent such accidents. 
Table 4. The association between presenting findings of the patients and their GCS scores is demonstrated

\begin{tabular}{|c|c|c|c|c|c|c|c|}
\hline & \multicolumn{5}{|c|}{ 1-Year GOS } & & \multirow[t]{2}{*}{$\mathbf{p}$} \\
\hline & Median & Percentile 25 & Percentile 75 & Median & Percentile 25 & Percentile 75 & \\
\hline Age (year) & 3.83 & 1.42 & 10.75 & 4.79 & 1.92 & 9.17 & 0.856 \\
\hline Admission GCS & 5.50 & 3.00 & 6.00 & 13.00 & 11.00 & 14.00 & $<0.001$ \\
\hline Admission blood sugar (mg/dL) & 227.00 & 164.00 & 364.00 & 129.00 & 113.00 & 170.00 & $<0.001$ \\
\hline Heart beat per minute & 128.00 & 94.00 & 150.00 & 120.00 & 103.00 & 140.00 & 0.928 \\
\hline Body temperature (oC) & 36.00 & 35.50 & 36.40 & 36.55 & 36.40 & 36.70 & $<0.001$ \\
\hline
\end{tabular}

GOS: Glasgov outcome scale, GCS: Glasgov coma scale.

Head trauma may be in the form of isolated head trauma or multi-trauma with abdominal or thoracic injuries. In our series 49 patients had isolated head traumas.

In 31 of the remaining 47 multi-trauma patients, head trauma was in the foreground. The admission GCS scores were significantly lower in multi-trauma patients who presented also with head trauma, which indirectly indicated poor prognosis.

The prognostic informative feature of classification of head trauma according to GCS is indisputable. First of all, health care professionals should gain information about the severity, outcome of injury, and prognosis of the patients by subjecting them to this scoring system. Making this classification also guides the treatment. In mild head trauma where conservative treatments such as follow-up, analgesics, and antiemetics are usually sufficient, whereas further medical treatments may be required to reduce ICP in moderate head trauma ${ }^{[16]}$.

The management of severe head trauma is completely different. Early recognition, and follow-up of the findings of raised ICP and keeping it within normal limits with treatment determines the outcome of the treatment ${ }^{[10,17]}$. In this study, a favourable outcome was obtained in all (100\%) cases with mild and moderately severe head trauma, and $72.2 \%$ of the patients with severe head trauma. In conclusion, all patients who died as a result of head trauma belong to the group of severe head trauma. These data clearly demonstrate the therapeutic importance, and the prognostic value of GCS classification of head trauma [13].

In consideration of the relationship between findings at admission, GCS and GOS scores should be calculated to determine whether these variables have prognostic value. Blood sugar levels, mean blood pressure, heart rate, body temperature, hypoxic status, application of CPR, pupillary areflexia, presence of shock, neurological deterioration and treatment with mechanical ventilation were examined at admission in our series, and patients who underwent CPR, those with pupillary areflexia, anisocoria, neurological deterioration, individuals in shock, and those under mechanical ventilation had lower GCS values and worse prognosis. It has been reported in the literature that hyperglycemia is an independent risk factor for poor prognosis ${ }^{[18,19]}$. In our series, hyperglycemia was seen as a poor prognostic factor in accordance with the literature. Hypothermia, hypoxia and hypotension are also known to predict poor prognosis $[20,21]$. In our series, hypothermia was associated with low GCS scores.

While ICP rarely increases in mild head trauma, it is a common finding in moderate and severe head trauma. Especially in severe head trauma, increase in ICP is almost inevitable. While observation in mild head trauma is generally sufficient, in moderately severe head trauma clinical course and neurological status of the patients are carefully monitored and ICP-lowering medications are administered $[10,16,22,23]$.

Hyperosmolar treatment given because of its anti-edematous, and ICP lowering effect consists of mannitol and hypertonic saline. Although both have been widely used to lower ICP, the use of hypertonic saline has increased in recent years ${ }^{[24]}$. In our ICU, hyperosmolar therapies used to lower ICP are administered as infusions of $20 \%$ mannitol at a dose of $0.5-1 \mathrm{~g} / \mathrm{kg}$ or hypertonic saline $(3 \% \mathrm{NaCl})$ $(3 \% \mathrm{NaCl})$ at a dose of $2-5 \mathrm{meq} / \mathrm{kg}$ within $10-20 \mathrm{~min}$ in parallel with the pediatric traumatic brain injury guidelines. In terms of complications of this treatment, blood osmolarity is closely monitored on the basis of pediatric guidelines ${ }^{[25]}$.

Routine ICP monitoring is recommended in severe head trauma ${ }^{[10]}$. All medical treatments should be administered as indicated in the guideline and at doses specified to keep ICP below $20 \mathrm{mmHg}$, and SBP above $40-50 \mathrm{mmHg}$. 
In spite of all medications, if ICP still remains above 20 $\mathrm{mmHg}$, the patient undergoes bilateral extended frontotemporoparietal decompressive craniectomy [26, 27]. Evacuation of hematomas, and correction of depressed fractures requiring surgery, insertion of ICP monitoring kit in severe head trauma, CSF drainage and decompressive craniectomy are performed by the neurosurgery team. In our series, hematoma surgery was performed in 10, ICP monitoring in 9, and decompressive craniectomy in 10 patients. Favourable outcomes were noted in two of 10 patients who underwent hematoma surgery, in 1 of 9 patients who received ICP monitoring and in only one of 10 patients who had decompressive craniectomy at the postoperative first year.

The reason for poor outcomes in this group was related tothe fact that 17 out of 18 patients belonged to the group of severe head trauma. These data clearly show the extremely worse prognosis of this patient group with an average GCS score of 5.2. On the other hand, the proper use of analgesia and sedation is very important in terms of preventing the increase in ICP due to pain caused by invasive interventions, insertion of central venous lines and mechanical ventilation. However, prolonged administration of these drugs masks the findings of neurological examination [10]. Because of the risk of reducing CPP, bolus administration of midazolam and/or fentanyl to lower ICP is not recommended ${ }^{[28]}$.

Prolonged propofol infusion is not recommended for sedation or the management of refractory increase in ICP. However, in spite of all medications, if ICP cannot be reduced, then, barbiturate coma may be applied provided that close monitoring of ICP is performed ${ }^{[29]}$.

In general, seizure thresholds of infants and children are known to be relatively lower and this rate increases up to $70 \%$ in severe head trauma ${ }^{[30]}$. Seizures were seen in 11 patients in our series and all of these patients were in the severe head trauma group (mean GCS: 3.6). Therefore, seizure prophylaxis is recommended for the prevention of early (first 7 days) posttraumatic seizures. Although there is insufficient evidence to demonstrate the superiority of levetiracetam over phenytoin ${ }^{[31]}$, in all pediatric head traumas in our center, the patient is routinely administered levetiracetam a loading dose of $40 \mathrm{mg} / \mathrm{kg}$ followed by a maintenance dose of $20 \mathrm{mg} / \mathrm{kg} /$ day.

Corticosteroids are not recommended in both pediatric patients and adults, and this is clearly stated in the current guidelines ${ }^{[10,32]}$. In our center, steroids are not used in the treatment of head trauma in parallel with the guidelines.

\section{Conclusion}

Pediatric head trauma patients should be followed up and treated in a multidisciplinary approach by neurosurgery and pediatric ICUs of the centers experienced in the management of trauma in the light of current guidelines. Knowing the characteristics of the injury and prognostic factors will guide the determination of the steps to be followed. Neurosurgery and pediatric ICU specialists can establish a common algorithm and standardize their approaches which will contribute positively to prognosis.

\section{Peer-review: Externally peer-reviewed.}

Authorship Contributions: Concept: M.S.G.; Design: M.S.G.; Data Collection or Processing: M.D.; Analysis or Interpretation: M.D.; Literature Search: M.S.G.; Writing: M.S.G.

Conflict of Interest: None declared.

Financial Disclosure: The authors declared that this study received no financial support.

\section{References}

1. Chaitanya K, Addanki A, Karambelkar R, Ranjan R. Traumatic brain injury in Indian children. Childs Nerv Syst 2018;34:111923.

2. Griffiths H, Goyal MS, Pineda JA. Brain metabolism and severe pediatric traumatic brain injury. Childs Nerv Syst 2017;33:1719-26.

3. Araki T, Yokota H, Morita A. Pediatric Traumatic Brain Injury: Characteristic Features, Diagnosis, and Management. Neurol Med Chir (Tokyo) 2017;57:82-93.

4. Lumba-Brown A, Yeates KO, Sarmiento K, Breiding MJ, Haegerich TM, Gioia GA, et al. Centers for Disease Control and Prevention Guideline on the Diagnosis and Management of Mild Traumatic Brain Injury Among Children. JAMA Pediatr 2018; 172:e182853.

5. Yue JK, Winkler EA, Burke JF, Chan AK, Dhall SS, Berger MS, et al. Pediatric sports-related traumatic brain injury in United States trauma centers. Neurosurg Focus 2016;40:E3.

6. Bell MJ, Adelson PD, Wisniewski SR; Investigators of the ADAPT Study. Challenges and opportunities for pediatric severe TBIreview of the evidence and exploring a way forward. Childs Nerv Syst 2017;33:1663-7.

7. Corso P, Finkelstein E, Miller T, Fiebelkorn I, Zaloshnja E. Incidence and lifetime costs of injuries in the United States. Inj Prev 2006;12:212-8.

8. Jagannathan J, Okonkwo DO, Yeoh HK, Dumont AS, Saulle D, Haizlip J, et al. Long-term outcomes and prognostic factors in pediatric patients with severe traumatic brain injury and elevated intracranial pressure. J Neurosurg Pediatr 2008;2:240-9.

9. Yue JK, Rick JW, Deng H, Feldman MJ, Winkler EA. Efficacy of decompressive craniectomy in the management of intracra- 
nial pressure in severe traumatic brain injury. J Neurosurg Sci 2019;63:425-40.

10. Kochanek PM, Tasker RC, Carney N, Totten AM, Adelson PD, Selden NR, et al. Guidelines for the management of pediatric severe traumatic brain injury, third edition: update of the brain trauma foundation guidelines: Erratum. Pediatr Crit Care Med 2019;20:1-82.

11. Stocchetti N, Conte V, Ghisoni L, Canavesi K, Zanaboni C. Traumatic brain injury in pediatric patients. Minerva Anestesiol 2010;76:1052-9.

12. Marshall LF, Marshall SB, Klauber MR, Van Berkum Clark M, Eisenberg HM, Jane JA, et al. A new classification of head injury based on computerized tomography. J Neurosurg 1991;75:14-20.

13. Teasdale G, Jennett B. Assessment of coma and impaired consciousness. A practical scale. Lancet 1974;2:81-4.

14. Muizelaar JP, Marmarou A, DeSalles AA, Ward JD, Zimmerman RS, Li Z, et al. Cerebral blood flow and metabolism in severely head-injured children. Part 1: Relationship with GCS score, outcome, ICP, and PVI. J Neurosurg 1989;71:63-71.

15. Sharples PM, Stuart AG, Matthews DS, Aynsley-Green A, Eyre JA. Cerebral blood flow and metabolism in children with severe head injury. Part 1: Relation to age, Glasgow Coma Score, outcome, intracranial pressure, and time after injury. J Neurol Neurosurg Psychiatry 1995;58:145-52.

16. Wang H, Cao H, Zhang X, Ge L, Bie L. The effect of hypertonic saline and mannitol on coagulation in moderate traumatic brain injury patients. Am J Emerg Med 2017;35:1404-7.

17. Tilford JM, Aitken ME, Anand KJ, Green JW, Goodman AC, Parker JG, et al. Hospitalizations for critically ill children with traumatic brain injuries: A longitudinal analysis. Crit Care Med 2005;33:2074-81.

18. Salim A, Hadjizacharia P, Dubose J, Brown C, Inaba K, Chan LS, et al. Persistent hyperglycemia in severe traumatic brain injury: an independent predictor of outcome. Am Surg 2009;75:25-9.

19. Shi J, Dong B, Mao Y, Guan W, Cao J, Zhu R, et al. Review: Traumatic brain injury and hyperglycemia, a potentially modifiable risk factor. Oncotarget 2016;7:71052-61.

20. Madden LK, DeVon HA. A Systematic Review of the Effects of Body Temperature on Outcome After Adult Traumatic Brain Injury. J Neurosci Nurs 2015;47:190-203.

21. Jeremitsky E, Omert L, Dunham CM, Protetch J, Rodriguez A. Harbingers of poor outcome the day after severe brain injury: hypothermia, hypoxia, and hypoperfusion. J Trauma 2003;54:312-9.
22. Kuppermann N, Holmes JF, Dayan PS, Hoyle JD Jr, Atabaki SM, Holubkov R, et al; Pediatric Emergency Care Applied Research Network (PECARN). Identification of children at very low risk of clinically-important brain injuries after head trauma: a prospective cohort study. Lancet 2009;3;374:1160-70.

23. Kukreti V, Mohseni-Bod H, Drake J. Management of raised intracranial pressure in children with traumatic brain injury. J Pediatr Neurosci 2014;9:207-15.

24. Bennett TD, Statler KD, Korgenski EK, Bratton SL. Osmolar therapy in pediatric traumatic brain injury. Crit Care Med 2012;40:208-15.

25. Gonda DD, Meltzer HS, Crawford JR, Hilfiker ML, Shellington DK, Peterson BM, et al. Complications associated with prolonged hypertonic saline therapy in children with elevated intracranial pressure. Pediatr Crit Care Med 2013;14:610-20.

26. Josan VA, Sgouros S. Early decompressive craniectomy may be effective in the treatment of refractory intracranial hypertension after traumatic brain injury. Childs Nerv Syst 2006;22:1268-74.

27. Jagannathan J, Okonkwo DO, Dumont AS, Ahmed H, Bahari A, Prevedello DM, et al. Outcome following decompressive craniectomy in children with severe traumatic brain injury: a 10-year single-center experience with long-term follow up. J Neurosurg 2007;106:268-75.

28. Welch TP, Wallendorf MJ, Kharasch ED, Leonard JR, Doctor A, Pineda JA. Fentanyl and midazolam are ineffective in reducing episodic intracranial hypertension in severe pediatric traumatic brain injury. Crit Care Med 2016;44:809-18.

29. Chen HI, Malhotra NR, Oddo M, Heuer GG, Levine JM, LeRoux PD. Barbiturate infusion for intractable intracranial hypertension and its effect on brain oxygenation. Neurosurgery 2008;63:880-6.

30. Herman ST, Abend NS, Bleck TP, Chapman KE, Drislane FW, Emerson RG, et al; Critical Care Continuous EEG Task Force of the American Clinical Neurophysiology Society. Consensus statement on continuous EEG in critically ill adults and children, part I: Indications. J Clin Neurophysiol 2015;32:87-95.

31. Chung MG, O'Brien NF. Prevalence of early posttraumatic seizures in children with moderate to severe traumatic brain injury despite levetiracetam prophylaxis. Pediatr Crit Care Med 2016;17:150-6.

32. Edwards $P$, Arango M, Balica L, Cottingham R, El-Sayed $H$, Farrell $\mathrm{B}$, et al; CRASH trial collaborators. Final results of $M R C$ $\mathrm{CRASH}$, a randomised placebo-controlled trial of intravenous corticosteroid in adults with head injury-outcomes at 6 months. Lancet 2005;365:1957-9. 